\title{
O trabalho na educação em saúde sob a perspectiva da ergologia de Yves Schwartz
}

\author{
Work in health education from the perspective of yves schwartz's ergology \\ El trabajo en la educación en salud bajola perspectiva de la ergología de Yves Schwartz
}

\author{
Mariane Bittencourt ${ }^{\mathrm{i}}$ \\ Helena Doege ii \\ Claudia Regina Lima Duarte da Silva ${ }^{\text {iii }}$
}

\begin{abstract}
Resumo: Este estudo é parte de uma pesquisa que objetivou compreender a percepção dos trabalhadores da saúde sobre suas práticas em educação em saúde. Compõe uma pesquisa-ação de abordagem qualitativa, realizada com 39 trabalhadores de diversas categorias atuantes em equipes da Estratégia de Saúde da Família de Blumenau/SC. Realizou-se 8 grupos focais gravados em áudio e transcritos. O conteúdo foi analisado à luz dos pressupostos da Ergologia de Yves Schwartz. Os trabalhadores demonstraram dificuldade em apontar o referencial teórico-metodológico para o trabalho com educação em saúde, enfatizaram a utilização de instrumentos funcionais às experiências. Identificaram as diferenças entre o trabalho prescrito e o trabalho real. A pesquisa se constituiu em espaço de debate de normas e práticas dos trabalhadores da saúde. Concluiu-se com a necessidade de criar espaços de debates das normas e renormalização da atividade laboral no serviço de saúde.
\end{abstract}

\begin{abstract}
This study is part of a research aimed at understanding the perception of health workers about their practices in health education. It comprises a qualitative approach research-action carried out with 39 workers from different categories working in Family Health Strategy teams of Blumenau / SC. There were 8 focus groups recorded in audio and later transcribed. The content was analyzed from the perspective of Yves Schwartz's Ergology. Workers showed difficulty in pointing out the theoretical-methodological framework for working with health education, emphasizing the use of instruments functional to their experiences. They identified differences between prescribed work and real work. The research constituted a space for the debate on norms and practices of health workers. It was concluded that there is need to create spaces for debates on norms and renormalization of the work activity in the health service.
\end{abstract}

Resumen: Este estudio forma parte de una investigación que tiene como objetivo comprenderla percepción de los trabajadores de la salud sobre sus prácticas en educación en salud. Constituye una investigación/acción de abordaje cualitativo, realizada con 39 trabajadores de diversas categorías que actúan en equipos de la Estrategia de Salud de la Familia de Blumenau/SC. Se realizaron 8 grupos focales grabados en audio y transcritos. El contenido fue analizado a la luz de las presunciones de la Ergología de Yves Schwartz. Los trabajadores demostraron dificultad enseñalar la referencia teórico metodológica para el trabajo con educación en salud, enfatizaron el uso de instrumentos funcionales para las experiencias. Identificaron las diferencias entre el trabajo prescrito y el trabajo real. La investigación se constituyó en espacio de debate de reglas y prácticas de los trabajadores de la salud. Se concluyó con la necesidad de crear espacios de debates de las reglas y renormalización de la actividad laboral en el servicio de salud.

Palavras-chave: Educação em saúde; Profissionais da saúde; Ergologia.

Keywords: Health education; Health personnel; Ergology.

Palabras claves: Educación en salud; Personal de salud; Ergología. 


\section{INTRODUÇÃO}

O Ministério da Saúde (MS) reorganiza e apoia a Atenção Básica (AB) visando o alcance das demandas de saúde e do cuidado integral da população como instituído na Constituição Federal e prescrito no Sistema Único de Saúde (SUS). O reflexo disto está na busca pela substituição do modelo tradicional de organização do cuidado em saúde, históricamente centrado na doença e no atendimento hospitalar, na tentativa de superar o modelo biomédico e o formato tradicional de ensino-aprendizagem. A AB é o nível mais primordial de um sistema de saúde e primeiro acesso a rede e é representada pela Estratégia de Saúde da Família (ESF) (BRASIL, 2012). O MS prescreve ações individuais e coletivas de promoção e proteção da saúde, prevenção de agravos, diagnóstico, tratamento, reabilitação e manutenção da saúde, que se iniciam na AB (BRASIL, 2006).

Nas ESF as ações voltadas à Promoção da Saúde (PS) acontecem através de práticas de Educação em Saúde (ES) que são tecnologias prescritas pelo SUS e correspondem a atendimentos e atividades grupais que possibilitam aos indivíduos, de forma dialética, reconhecerem-se em sua singularidade e enquanto seres sociais, estimulados à emancipação e autonomia. O MS define ES como "conjunto de práticas que contribuem para aumentar a autonomia das pessoas no seu cuidado e no debate com os profissionais e os gestores a fim de alcançar uma atenção de saúde de acordo com suas necessidades" (CONASS, 2015). Para isso, disponibiliza de uma série de Políticas e documentos que normatizam as atividades dos trabalhadores. Além disso, é enorme a diversidade de tecnologias e metodologias de ensino-aprendizagem para atuação com ES e cabe ao profissional, na sua atividade laboral, a escolha dos instrumentos a serem utilizados.

Do ponto de vista da ergologia de Schwartz sobre a atividade humana, podemos pensar o cotidiano do trabalho na $\mathrm{AB}$ em duas perspectivas: 1. aquilo que é prescrito pelas Políticas e documentos do SUS - que é exigido do profissional e faz parte do processo de trabalho na saúde (trabalho prescrito); e 2. o trabalho real, que condiz à ação do trabalhador na realidade, dentro de suas condições humanas e de conhecimento. Sendo assim, o objetivo deste estudo foi compreender a percepção dos trabalhadores da saúde sobre suas práticas em ES à luz dos pressupostos da Ergologia de Ives Schwartz.

\section{Metodologia}

Este estudo é parte de uma pesquisa que objetivou compreender a percepção dos trabalhadores da saúde sobre suas práticas em ES. Trata-se de uma pesquisa-ação de 
abordagem qualitativa, realizada com 39 profissionais de 4 ESF de Blumenau/SC. Para a produção dos dados foram realizados 8 grupos focais gravados em áudio e transcritos.

A técnica do grupo focal foi escolhida para a produção de dados por ser considerada capaz de auxiliar na investigação de informações e possibilitar a compreensão de percepções, crenças e atitudes sobre um tema, produto ou serviço (RYAN et al, 2014). Após a transcrição, as falas foram sistematizadas através da Análise de Conteúdo. O conteúdo foi analisado à luz dos pressupostos da Ergologia de Ives Schwartz.

O estudo respeitou os preceitos éticos da pesquisa com seres humanos exigidos pela Resolução No 466/2012 do Conselho Nacional de Saúde e foi aprovado pelo comitê de ética da Universidade Regional de Blumenau - FURB sob o parecer No 2.106.616.

\section{RESULTADOS E DISCUSSÕES}

As demandas voltadas à Educação na Saúde são deliberadas pela Secretaria de Gestão do Trabalho e da Educação na Saúde (SGTES), que orienta o ordenamento da formação, planejamento do setor do trabalho e provimento de trabalhadores. Nesse contexto, o Departamento de Gestão da Educação na Saúde (DEGES/SGTES) coordena a Política Nacional de Formação e Desenvolvimento de Trabalhadores para o SUS, promovendo a articulação entre três eixos fundamentais: a relação entre a educação e o trabalho; a mudança nas políticas de formação e nas práticas de saúde; a produção e a disseminação do conhecimento e a educação nos serviços. Outra ação estratégica é a coordenação da Política Nacional de Educação Permanente em Saúde, articulando compromissos entre órgãos do MS, Conselho Nacional de Saúde, Conselho Nacional de Secretários de Saúde e de Conselho Nacional de Secretarias Municipais de Saúde, Secretarias Estaduais e Municipais de Saúde, Conselhos Estaduais e Municipais de Saúde, Ministério da Educação, entidades de profissionais e de ensino das profissões da área da saúde, entidades estudantis e movimentos e práticas de educação popular em saúde (BRASIL, 2018).

As Políticas e entidades supracitadas dispõem de materiais técnicos que são indispensáveis à tomada de decisões no cotidiano da atenção a saúde e que podem ser incorporados como ferramentas capazes de orientar as ações dos trabalhadores da saúde. Estas ferramentas teórico-metodológicas para o trabalho podem ser chamadas de prescrições exigidas ao profissional e que fazem parte do processo de trabalho na saúde. Porém, a ergologia entende que "o trabalhador renormaliza o trabalho prescrito e produz o que resulta no trabalho real. Assim, a atividade real(izada) tem, invariavelmente, uma distância do trabalho prescrito e é sempre permeada por contradições e coincidências" (BERTONCINI, 
2011, p.28). Com isso, a ergologia utiliza o conceito de atividade humana de forma em que diferencia o trabalho prescrito (normas antecedentes) do trabalho real (na ação do trabalhador).

A medida em que os trabalhadores descreviam as práticas em ES se percebia a necessidade do intercâmbio entre saberes técnicos e vivenciais. Constataram a importância da bagagem acadêmica para a atuação, mas enfatizaram que os recursos utilizados eram, na maioria das vezes, fundamentados por suas experiências individuais. Ao serem questionados sobre o suporte teórico-técnico-metodológico oferecidos pelos materiais disponibilizados pelo MS, demonstraram dificuldade em nomear tais instrumentos.

De teoria a gente não tem nada, né. Só de prática (ESFC/P10).

A gente não tem nenhum instrumento [...] na faculdade a gente já ouviu, mas depois não tive mais isso presente conceitualmente no dia a dia, então não sei nem te dar um conceito teórico (ESFD/P1).

Os saberes acadêmicos também fazem parte do rol de experiências do trabalhador, portanto, invariavelmente influenciam suas formas de olhar e atuar com ES, independente de o identificarem como 'tal teoria' ou 'tal técnica'. A ergologia entende que a aprendizagem formal jamais pode ser descartada, mas pode e deve ser enriquecida de uma aprendizagem informal relativa ao que os trabalhadores criam e recriam nas suas próprias vivências (SCHWARTZ et al, 2007).

Me vi em uma situação onde "tu faz ou tu faz". Eu fui jogada a fazer isso. 'Ou eu faço, ou eu faço'. [...] Hoje é mais tranquilo, nem preciso ficar lendo, se fui eu que fiz o material eu já sei tudo decorado (ESFC/P10).

Dois pontos importantes podem ser pensados a partir das falas acima: a motivação do trabalhador para a pesquisa e apropriação do material disponibilizado como suporte à sua atividade; e a necessidade de um ambiente de trabalho que promova o debate de normas, uma vez que seja dada voz às subjetividades e entenda as motivações dos trabalhadores, possibilitando assim a renormalização do trabalho, 'o fazer de outra forma'. A análise do 
trabalho em curso como atividade permite alcançar o modo como o trabalhador enfrenta as singularidades em situações de trabalho que não comportam as prescrições (SCHWARTZ et al., 2007).

Todos participantes da pesquisa associaram as inquietações sobre a atividade em ES à utilização de uma metodologia tradicional de ensino-aprendizagem e ao fato de muitas vezes atrelarem as ações à consulta e à barganha: brindes, passeios, lanches, entrega de fitas de glicemia, alegando como recursos de estímulo e, consequentemente expectativa de maior adesão dos usuários. Sobre tal metodologia, afirmam:

É como uma aula onde o usuário tem que ficar quieto escutando um repasse de conhecimento, que na maioria das vezes foca nos problemas, na doença (ESFB/P5).

Os trabalhadores se percebem apropriados de conhecimento teórico-técnico das áreas da saúde, destacam dificuldades com a metodologia que utilizam, mas se experimentam de mãos atadas frente a resolubilidade desta problemática presente na rotina de trabalho. Ao pensar estratégias para mudar a realidade frente a metodologia, apontaram atitudes como: promover ambiente prazeroso, estar disposto a aprender a ensinar, compartilhar experiências, questionando as pessoas para entendê-las e para que elas se entendam e tenham autonomia para cuidar de si.

Pode-se observar ruídos na compreensão quanto às prescrições para o trabalho com ES e dificuldades na flexibilização com o trabalho real, de reconhecimento e autorização do uso de si, de saberes e competências. Holz e Bianco (2014) afirmam que uma vez que o trabalho é um uso de si e envolve as escolhas e arbitragens do trabalhador, implica no "ato de tentar viver de acordo consigo mesmo num ambiente em parte imposto, em parte coercitivo, mas em parte modificável e esse processo será sempre debatido e renormalizado por usos de si no âmbito das entidades coletivas de trabalho" (HOLZ; BIANCO, 2014, p.501).

Os trabalhadores identificaram alguma forma de gestão do debate de normas em situações pontuais da vida laboral, onde se distanciaram da noção de "tarefa cumprida" e expermimentaram satisfação na ação do trabalho. Perceberam que houve transformações da atividade. Como exemplo, uma das equipes frizou como "divisor de águas", o ingresso de uma trabalhadora de pós-graduação. Na experiência acadêmica a trabalhadora foi convocada 
a se aproximar do seu debate de normas e renormalizar sua atividade e, ao compartilhar tal experiência, conduziu a equipe para rever suas normas e repensar o cotidiano. Relataram a inquetude frente às práticas de ES e o processo de trabalho em si e dificuldade na adesão dos usuários nos grupos.

É um grande desafio pra nós profissionais e também para a comunidade, pelo fato de que a gente tem identificado que a forma tradicional de fazer grupo não tem dado certo, a questão das palestras, como era logo que a gente iniciou enquanto ESF, né? A gente percebeu que onde existe a palestra, as pessoas não participam e acaba ficando cansativo (ESFA/P1).

Constataram alguns resultados frente à transformação da prática mediada pelo debate de normas: aumento do número de participantes, maior frequência e envolvimento dos usuários, usuários referindo melhora na situação de saúde e formação de vínculo.

A mobilização dos trabalhadores oportunizou o diálogo, mudança no trabalho e alcance dos objetivos. Sendo assim, os saberes construídos no próprio processo de trabalho, movido pela atividade humana, os tornou responsáveis pela eficácia do trabalho.

Sobre esse cenário, Schwartz, Duc e Durrive (2007, p.24) afirmam que “[...] a ideia de atividade é sempre um 'fazer de outra forma', um 'trabalhar de outra forma”. Ou seja, os trabalhadores reorganizaram o que lhes estava prescrito fazendo escolhas a partir das suas experimentações. Esse movimento para a transformação mostra que se torna impossível apenas utilizar os conceitos do conhecimento teórico na ação do trabalho, pois inevitavelmente são tecidos pelas experiências vivenciais que influenciam a ação. SIMON et al (2014) enfatizam que as mudanças não se dão apenas pela metodologia utilizada, mas pela motivação, intenção e disposição política daquele que a utiliza - o educador, o trabalhador da saúde. "Um educador comprometido com a transformação social pode fazer de uma aula expositiva um momento de diálogo, enquanto que o comprometido com a manutenção pode manter relações de opressão na roda de conversa, por exemplo" (SIMON et al, 2014, p.1360).

Ao passo que elaboravam suas práticas, os trabalhadores de todas ESF se demonstravam entusiasmados a tomar atitudes transformadoras da realidade insatisfatória, tomados da consciência sobre a importância do debate de normas individuais e coletivas. Os trabalhadores construíram um material escrito onde, a partir das reflexões construídas na 
pesquisa, listaram itens para debate nas próximas reuniões de equipe para planejamento das ações.

O trabalho é uma atividade intelectual e para executá-lo é necessário pensar antes. Do mesmo modo que é preciso aprender a fazer, também se aprende fazendo. Toda atividade exige a aplicação de um protocolo, mas também, exige um encontro de encontros a gerir. Por mais prescritiva que seja a tarefa, o que vai guiar e realizar será também o conhecimento acerca da situação de trabalho.

\section{CONSIDERAÇÕES FINAIS}

A pesquisa permitiu a reflexão sobre a atividade, promovendo espaço para que os trabalhadores renormalizassem o trabalho prescrito e entendessem a complexidade humana refletida no trabalho real. Afinal, aproximar-se do cotidiano do trabalhador da saúde é dar vOz e propiciar a superação da experimentação do simples cumprimento daquilo que lhe é exigido, promovendo espaço de renormalização para gestão da própria situação de trabalho. Levando em consideração o conhecimento produzido por Schwartz, criou-se lugar para o debate de normas e valores, afim de compreender a percepção sobre suas práticas em ES.

De um lado, os trabalhadores da área da saúde têm uma grande variedade teórica e metodológica para sustentar suas ações; de outro, observa-se o trabalho conduzido pelas vivências particulares dos trabalhadores, pautados também nas necessidades de cada território, e através de valores e normas além dos instituídos pela formação profissional, o que requer a necessidade de se repensar a atividade enquanto prática de ensino-aprendizagem na ES. Sendo assim, concluiu-se que há a necessidade pela continuidade de momentos como estes, criando mais espaços de debates das normas e renormalização da atividade laboral.

\section{REFERÊNCIAS}

BERTONCINI, J. H. Entre o prescrito e o real: renormalizações possíveis no trabalho da enfermeira na Saúde da Família. Tese (Doutorado em Enfermagem), Programa de PósGraduação em Enfermagem, Centro de Ciências da Saúde, Universidade Federal de Santa Catarina, Centro de Ciências da Saúde, Florianópolis, 2011.

BRASIL. Conselho Nacional de Secretários de Saúde. A Atenção Primária e as Redes de Atenção à Saúde / Conselho Nacional de Secretários de Saúde. - Brasília: CONASS, 2015.

Ministério da saúde. Conselho Nacional de Saúde. Coletânia de Normas para o Controle Social no Sistema Único de Saúde. Brasília, DF, 2006. 208 p. Disponível em: <http://conselho.saude.gov.br/biblioteca/livros/coletanea_miolo.pdf>. Acesso em: 13 jul. 2019. 
Ministério da Saúde. Secretaria de Atenção à Saúde. Departamento de Atenção Básica. Política nacional de atençao básica. Brasília, DF, 2012. 110 p. Disponível em: <http://bvsms.saude.gov.br/bvs/publicacoes/politica_nacional_atencao_basica.pdf $>$. Acesso em: 12 jul. 2019.

Ministério da Saúde. Secretaria de Gestão do Trabalho e da Educação na Saúde. Departamento de Gestão da Educação na Saúde. Política Nacional de Educação Permanente em Saúde: o que se tem produzido para o seu fortalecimento? / Ministério da Saúde, Secretaria de Gestão do Trabalho e da Educação na Saúde, Departamento de Gestão da Educação na Saúde - 1. ed. rev. - Brasília: Ministério da Saúde, 2018.

Ministério da Saúde. Secretaria de Gestão do Trabalho e da Educação na Saúde. Departamento de Gestão em Saúde. Política nacional de educação permanente em saúde. Brasília, DF, 2009. 64 p. Disponível em:

$<$ http://portal.anvisa.gov.br/documents/33856/396770/Pol\%C3\%ADtica+Nacional+de + Educa $\%$ C3\%A7\%C3\%A3o+Permanente+em + Sa $\%$ C3\%BAde/c92db117-e170-45e79984-8a7cdb111faa>. Acesso em: 12 jul. 2019.

HOLZ, E. B; BIANCO, M. de F. Ergologia: uma abordagem possível para os estudos organizacionais sobre trabalho. Cad. EBAPE.BR, Rio de Janeiro, v. 12, n. spe, p. 494-512, aug. 2014. Disponível em:

$<$ http://www.scielo.br/scielo.php?script=sci_arttext\&pid=S1679-

39512014000700008\&lng=en\&nrm=iso >. Acesso em: 13 jul. 2019.

MINAYO, M. C. S. O desafio do conhecimento: pesquisa qualitativa em saúde. 10. ed. São Paulo: Hucitec. 2013.

RYAN, K. E.; GANDHA, T.; CULBERTSON, M. J.; CARLSON, C. Focus group evidence implications for design and analysis. American Journal of Evaluation, v. 35, n. 3, p. 328-345. 2014. Disponível em: <http://doi.org/10.1177/1098214013508300>. Acesso em: 10 jul. 2019.

SCHWARTZ, Y. Circulações, dramáticas, eficácias da atividade industriosa. Revista Trabalho, Educação \& Saúde, Rio de Janeiro, v. 2, n. 1, p. 33-35, 2004.

SCHWARTZ, Y. Entrevista: Yves Schwartz. Trabalho, Educação e Saúde, v. 4, n. 2, p. 457- 466. 2006. Disponível em: <http://www.scielo.br/pdf/tes/v4n2/15.pdf>. Acesso em: 11 jul. 2019.

SCHWARTZ, Y. et al. O trabalho se modifica. In: SCHWARTZ, Yves; DURRIVE, Louis. (Orgs.). Trabalho e ergologia: conversas sobre a atividade humana. Tradução de Jussara Brito et al. Niterói: EdUFF, 2007. p. 23-47.

SCHWARTZ, Y. Trabalho e uso de si. Revista Pro-Posições, v. 1, n. 5, p. 32, 2000.

SCHWARTZ, Y. Conceituando o trabalho, o visível e o invisível. Revista Trabalho, Educação \& Saúde, Rio de Janeiro, v. 9, 2011.

SIMON, E. et al. Metodologias ativas de ensino-aprendizagem e educação popular: encontros e desencontros no contexto da formação dos profissionais de saúde. Interface (Botucatu), Botucatu, v. 18, supl. 2, p. 1355-1364, 2014. Disponível em: 
<http://www.scielo.br/scielo.php?script=sci_arttext\&pid=S141432832014000601355\&lng=en\&nrm=iso>. Acesso em: 13 jul. 2019.

i Psicóloga. Mestre em Saúde Coletiva pela Universidade Regional de Blumenau - FURB. Especialização em Psicologia Hospitalar e da Saúde pela SOCIESC. Participante no Grupo de Pesquisa Promoção à Saúde e Integralidade do Cuidado no Programa de Mestrado Profissional em Saúde Coletiva da FURB. Docente do ensino superior no Centro Universitário Dante - UNIDANTE, Blumenau/SC. E-mail: psimariane@hotmail.com

ii Enfermeira. Mestranda em Saúde Coletiva pela Universidade Regional de Blumenau - FURB. Especialização em Multiprofissional em Atenção Básica pela Universidade Federal de Santa Catarina (UFSC). Especialização em Formação Integrada Multiprofissional em Educação Permanente em Saúde pela Universidade Federal do Rio Grande do Sul (UFRGS). Participante no Grupo de Pesquisa Promoção à Saúde e Integralidade do Cuidado no Programa de Mestrado Profissional em Saúde Coletiva da FURB. Servidora Pública na Prefeitura Municipal de Benedito Novo-SC. E-mail: lenadoege@gmail.com

iii Enfermeira. Doutora em Enfermagem pela Universidade Federal de Santa Catarina - UFSC. Mestre em Educação pela Universidade Regional de Blumenau - FURB. Docente do Mestrado Profissional do Programa de Pós-Graduação em Saúde Coletiva, Blumenau/SC. E-mail: claudiaduarte1108@gmail.com 